\title{
Long-term Change in Lightning Mortality and Its Relation to Annual Thunder Days in Japan
}

\author{
Fumiaki Fujibe* \\ * Faculty of Urban Environmental Sciences, Tokyo Metropolitan University
}

(Received: Nov. 14, 2016 Accepted: Mar. 22, 2017)

\begin{abstract}
Long-term variations in annual lightning deaths in Japan were examined in relation to the number of thunder days, on the basis of death statistics for 1909 to 2014, and police data for 1968 to 2009. The number of lightning deaths was mostly 20 to 60 people without a remarkable trend before World War II, while it rose to over 100 just after the war, and then decreased during the latter half of the 20th century to less than 10 in recent decades. For the period before 1970, the number of annual lightning deaths was positively correlated with that of warm-season thunder days (averaged over 39 stations) with a correlation coefficient exceeding 0.5. The correlation became low and insignificant after the 1980s as lightning mortality decreased, although a high correlation of 0.6-0.8 was maintained between lightning damages and thunder days. There was also a positive correlation of 0.4-0.6 between lightning deaths and warm-season mean temperature until the 1980s, corresponding to a weak correlation between thunder days and temperature.
\end{abstract}

Key words Lightning Mortality, Lightning Deaths, Thunder Days, Vital Statistics

\section{INTRODUCTION}

As in many regions of the world, lightning is one of the causes of natural disaster in Japan. Lightning is most frequent in summer, especially in the inland region (Japan Meteorological Agency, 1968; Shindo et al., 2012; Ishii et al., 2014), where daytime heating enhances thermal instability causing the development of convective clouds. Lightning also occurs in winter on the northwestern coast of Honshu under an outbreak of cold air that is heated and moistened over the Sea of Japan. Kitagawa (1989) and Yoshida (2002) showed a long-term increasing trend of winter thunder days on the northwestern side of Honshu.

For lightning deaths in Japan, the data of the National Police Agency (NPA) have been used by some researchers to document their change in the latter half of the 20th century (Hatakeyama, 1970; Kitagawa, 2001; Holle, 2008, 2010, 2016). The data show that annual lightning deaths amounted to 20 people or more by the 1970s, but decreased to less than 10 in the 1990s. However, there is no documentation of lightning fatalities for a longer period including the early 20th century. Neither is there information on the relationship between lightning mortality and meteorological parameters.

The present study was conducted using death statistics compiled by the Ministry of Health, Labour and Welfare of Japan. The statistics are based on the International Classification of Diseases (ICD, http://www.who.int/classifications/icd/en/), and provide annual numbers of lightning deaths since 1909. The data are categorized by age and sex, as well as prefecture and month for some periods. The aim of the study is to document long-term changes in lightning mortality for over 100 years, and its relationship to meteorological parameters such as the annual number of thunder days and temperature.

\section{DATA}

\subsection{Lightning Mortality}

The ICD-based death statistics of Japan were published annually in "Statistics on Causes of Death" until 
1938 and in "Vital Statistics" thereafter. The item of lightning appeared in the second ICD (ICD-2), which entered into use in 1909 in Japan. Since then, ICD has been revised eight times as shown in Table 1, and the currently used version is ICD-10. The present study was made using data up to 2014. The area of statistics is almost unchanged during the analysis period, except the lack of data in Okinawa for 1947 to 1972 and other minor changes. Data for 1944 to 1946 are missing due to war.

Table 1 Diagnosis code for lightning death in each version of ICD

\begin{tabular}{ccc}
\hline \hline ICD & Code & Period in Japan \\
\hline 2 & 196 & $1909-1922$ \\
3 & 195 & $1923-1932$ \\
4 & 192 & $1933-1943$ \\
5 & 192 & $1947-1949$ \\
6 & E935 & $1950-1957$ \\
7 & E935 & $1958-1967$ \\
8 & E907 & $1968-1978$ \\
9 & E907 & $1979-1994$ \\
10 & X33 & $1995-$ \\
\hline
\end{tabular}

Data were provided for each sex and for four age categories of $0,1-14,15-59$, and $\geq 60$ years old until 1935. From 1940, data are available for each of the five-year age classes up to 90 years old, and up to 100 years old since 1947. It is also possible to obtain data for each of the 47 prefectures (not classified by age) for 1909 to 1942, 1947 to 1949, and 1999 onward. Monthly data are available for 1937 to 1941.

There is no indication of erroneous data except for a case in 1914, for which the number of lightning deaths in Akita Prefecture is recorded to be 43. This is more than an order of magnitude larger than other years (0.6 persons per year in Akita on average for 1909 to 1942 except 1914), despite the fact that there is no literature regarding a big lightning disaster in Akita in that year. It seems possible that some of the fatalities of the "Senhoku Earthquake", which killed 94 people in Akita in March 1914, were wrongly counted as lightning deaths, since the item of lightning death in "Statistics on Causes of Death" for 1909 to 1922 was labeled using the word shin-shi, which can be mistaken for "quake death."

For supplementary analysis, the data compiled by the NPA in "The White Paper of Police" for 1968 to 2009 were used. These data provide not only the number of deaths, but also the number of injuries and damages due to lightning.

Analysis of the mortality rate was conducted using population data compiled by the Government of Japan. The definition of mortality rate is provided in Appendix A.

\subsection{Meteorological Data}

Data on monthly thunder days at observatories of the Japan Meteorological Agency (JMA; reorganized from the Central Meteorological Observatory in 1956) are available in a data file of the JMA for the period from 1931 onwards, with some missing data in 1945. A thunder day is defined as a day on which lightning of any intensity and/or thunder of intensity 1 or 2 are observed (Japan Meteorological Agency, 2016). In this definition, intensity is based on a scale of three, 0,1 , and 2, which are judged subjectively by an observer. The present study was made using data at 39 stations that lie in Honshu, Shikoku, and Kyushu, and provide a continuous record up to 2014. The reason for limiting the area to the three main islands is that the majority of lightning deaths occur in this area (Fig. 8). Figure 1 shows the distribution of stations used for analysis. 

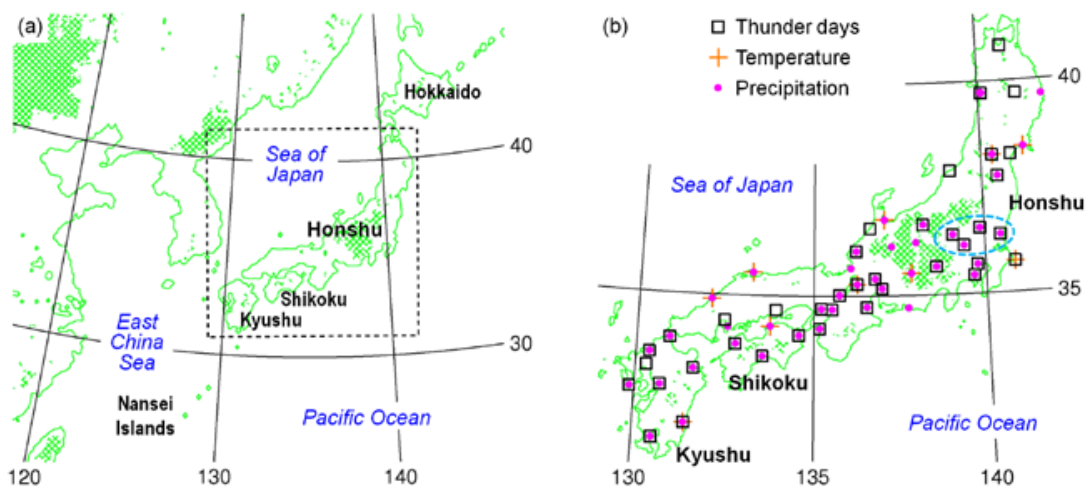

Fig.1 Maps of East Asia and the analysis area, and meteorological stations used for the analysis of thunder days, temperature, and precipitation. The region shown in dashed lines in (a) is the region shown in (b). Shade indicates an area above 1000 meters from sea level.

Since a thunder day is a quantity of only a fixed point, and does not give information on frequency and intensity of the lightning of the day, its representativeness as lightning activity over a region may be limited (Taszarek et al., 2015). Figure 2 shows the number of cloud-to-ground (CG) flashes over Japan for 2002 to 2008 (Ishii, 2012), and the number of thunder days averaged over the 39 stations. The former was analyzed using the data of the JMA's LF-wave lightning detection system that covers the most of Japan and its adjacent waters (Ishii et al., 2014). The year-to-year variation in thunder days, especially that for May to September, is found to have some similarity to that of CG flashes with respect to maxima in 2002, 2004, and 2008, although the agreement is not perfect. The interannual variation in thunder days also has partial similarity to that in CG flashes on another location network for 1992 to 2008 (Fig. 3 of Shindo et al., 2012). On this understanding, the number of thunder days was used for a correlation analysis concerning annual lightning deaths, because there is no other index of lightning activity available over decades. Figure 3 shows annual variations in thunder days and CG flashes. Both of them have sharp peaks in midsummer (July to August). However, the ratio of CG flashes to thunder days is much smaller in winter than in summer, reflecting the small number of lightning flashes in a winter thunder event (Hayashi and Marui, 2016).

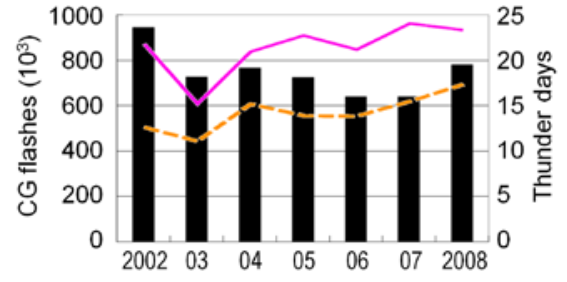

Fig.2 Interannual variations in cloud-toground (CG) flashes over Japan (bars; after Ishii (2012)), and thunder days (pink solid line for the whole year, and or ange da she d line $\mathrm{f}$ or $\mathrm{M}$ a $\mathrm{y}$ to September).

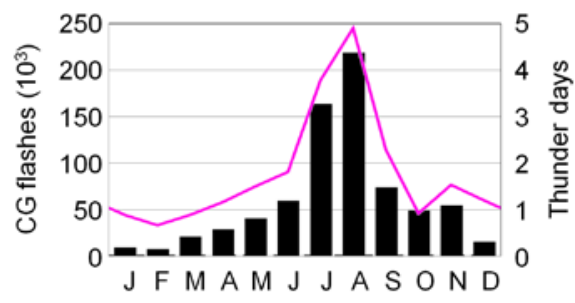

Fig.3 Seasonal variations in CG flashes over Japan (bars; after Ishii (2012)), and thunder days (pink solid line). 
For temperature, monthly and annual average data at 10 stations in Honshu, Shikoku, and Kyushu were used (Fig. 1). These stations partly comprise the 15 stations used by the JMA for monitoring climatic temperature change over Japan. For precipitation, data at 42 stations in the three main islands were used (Fig. 1). They belong to the 51 stations used for monitoring climatic precipitation change over Japan.

\section{STATISTICS OF LIGHTNING MORTALITY}

Figure 4 shows the time series of annual lightning mortality and thunder days. The number of deaths varied mostly between 20 and 60 before World War II, without an obvious long-term trend, and suddenly increased to over 100 in 1947 and 1948 after three years' blank due to war. After that, it decreased, and has stayed at fewer than 10 people since 1985. On the other hand, annual thunder days fluctuated at around 15 days until the 1970s, and then gradually increased in the recent few decades. However, an increasing trend of thunder days from May to September (hereafter denoted by the warm season) is not obvious, reflecting the fact that an increase in thunder days is mainly found in winter (Kitagawa, 1989; Yoshida, 2002).

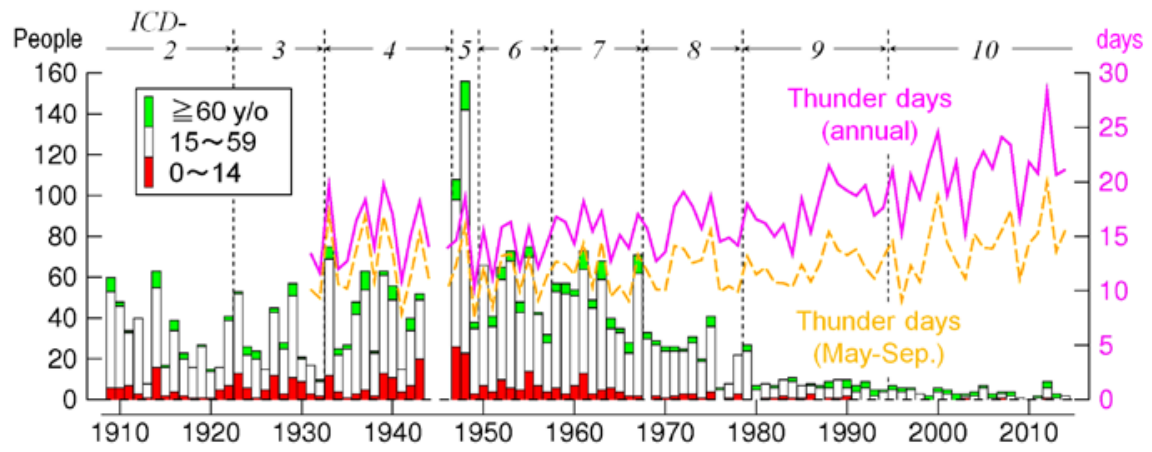

Fig.4 Annual lightning deaths for 1909 to 2014 except 1944 to 1946 (columns with the left scale), and thunder days for 1931 to 2014 except 1945 (lines with the right scale). Dotted vertical lines indicate the revision of ICD.

Figure 5 shows the time series of adjusted mortality rate for three age groups from 1947 to 2014, for which data are available for each fiveyear bin up to 100 years of age. An average over each four-year period is shown in logarithm. The nearly linear decrease on a logarithmic scale indicates an exponential decrease in the mortality rate. The linear regression in Fig. 5 yields a decrease rate of $7.4 \%$ /year for the 15-59 age group, and $5.7 \%$ /year for the $\geq 60$ age group. These values correspond to a decrease to $1 / 41$ and $1 / 17$ in 50 years, respectively. In comparison with these two age groups, mortality at the age of 14 years old and under is lower by a few times or more, and has also decreased rapidly. The mortality rate for all of the age groups (not shown) shows a decrease rate of $7.0 \%$ /year, corresponding to a decrease to $1 / 33$ in 50 years.

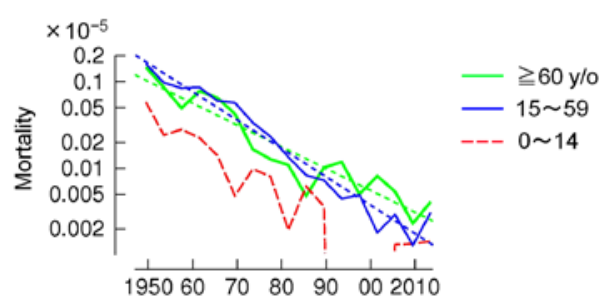

Fig.5 Trends of lightning mortality in each four-year period from 1947 to 2014 for three age groups. The ordinate is scaled in logarithm. Regression lines are shown for groups of 1559 and $\geq 60$ years old. 
Figures 6 and 7 show lightning deaths and the mortality rate in each age category for the first and the last 16 years in Fig. 5, namely, 1940-1958 (excluding 1944 to 1946) and 1999-2014. The number of deaths is highest at around 20 years of age for the former period, whereas it is highest in the 60s for the latter period. A shift toward higher ages is also found for mortality rate, but the change in age dependence between the two periods is less striking than that in the number of deaths. The different change between deaths and mortality rate is due to a relative increase in elderly people. The population of the 15-59 age group increased by 1.4 times between the two periods, while that of the $\geq 60$ age group increased by 5.0 times. This fact and the differential decreasing trends of mortality rate (Fig. 5) indicate that the relative increase in lightning deaths of elderly people is attributable to both the higher increase in population and the slower decrease in mortality than young and middleaged people. It is to be noted that the very high mortality of the age category of 90-94 for 1940 to 1958 (Fig. 7b) corresponds to only a man's death during the 16 years, in which the population of this age group was very small ( 8,742 people, which is $1 / 64$ of that of the latter period), so that mortality rose.
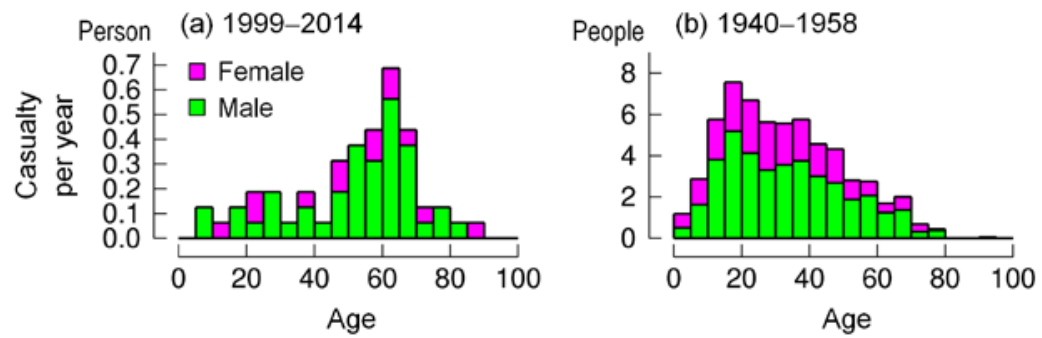

Fig.6 Lightning deaths for each five-year age group (0-4, ---, $\geq 95$ years old) for 1999 to 2014, and 1940 to 1958 (except 1944 to 1946).
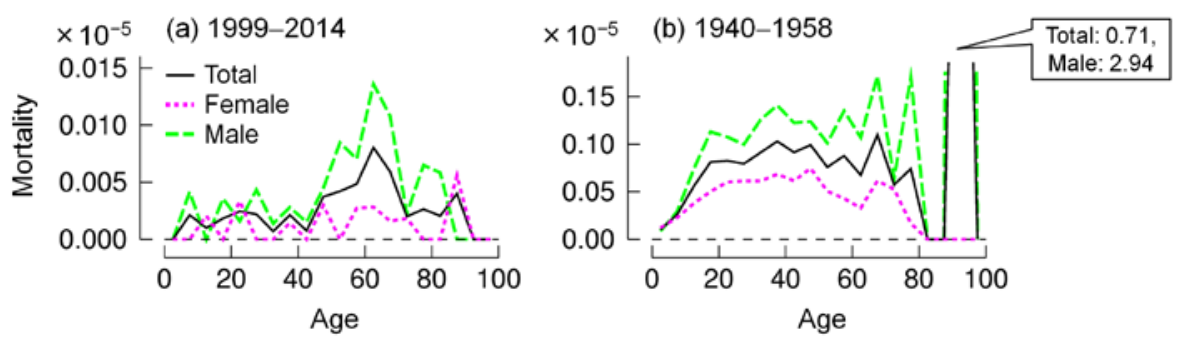

Fig.7 Lightning mortality for each five-year age group.

A brief analysis of regional and seasonal features was conducted for the early 20th century, in which lightning mortality was high. Figure 8 shows the mortality rate (unadjusted; see Appendix A) for each prefecture based on data for 1931 to 1949 (except 1943 to 1946). It can be seen that the mortality rate is high in inland Honshu and southern Kyushu. This distribution is similar to that of the lightning frequency in summer (Shindo et al., 2012; Ishii et al., 2014). For the 16 years from 1999 to 2014, however, each of the top two prefectures in Fig.8 (Tochigi and Gumma Prefectures) had only one lightning death. This fact implies that the distribution of mortality may have changed, but we refrain from entering into further analysis because lightning deaths are so scarce in recent years (eight people at most in a prefecture for 1999 to 2014). 


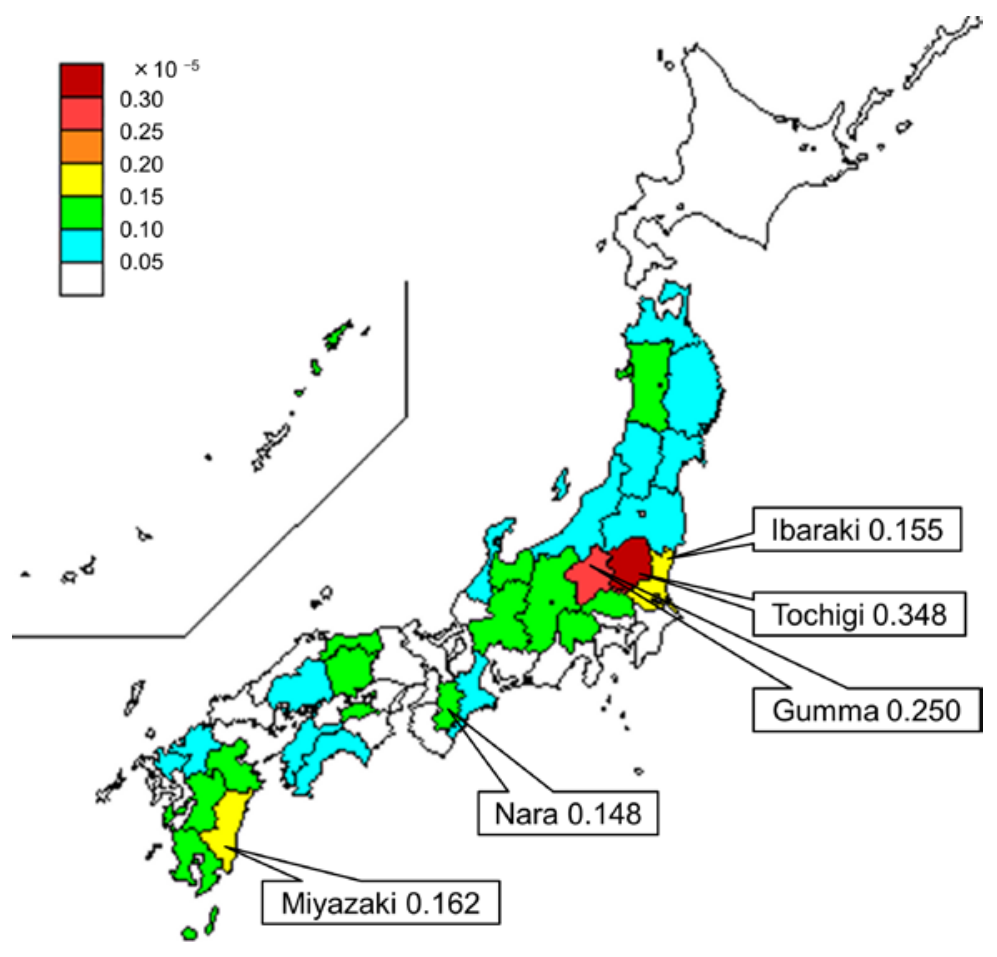

Fig.8 Lightning mortality (unadjusted) in each prefecture for 1931 to 1949 (except 1943 to 1946). The top five prefectures are shown in callouts.

Figure 9 shows the monthly statistics of lightning deaths for 1937 to 1941 . Over $95 \%$ of the total cases occurred from May to September with a peak in July to August. Although winter lightning sometimes causes damage to outdoor equipment and aircraft (Kobayashi et al., 2007), it appears to be of a lesser threat to life. This may be because of low outdoor activity in winter, as well as the sparsity of flashes in winter thunderstorms (Hayashi and Marui, 2016; Fig. 3).

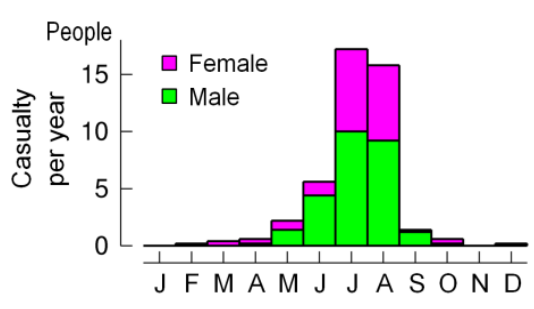

Fig.9 Monthly lightning deaths for 1937 to 1941.

Finally, time series of lightning casualties and damages in the NPA data are shown in Fig. 10. The number of lightning deaths in this dataset does not exceed that in the Vital Statistics except in 1987 (7 in the Vital Statistics and 14 in the NPA data). The ratio of deaths in the NPA data to those of the Vital Statistics is nearly constant, with an average of $78 \%$ for the first 10 years (1968 to 1977) and 75\% for the last 10 years (2000 to 2009). In other words, lightning deaths in the NPA data decreased at nearly the same rate as those in the Vital Statistics. 


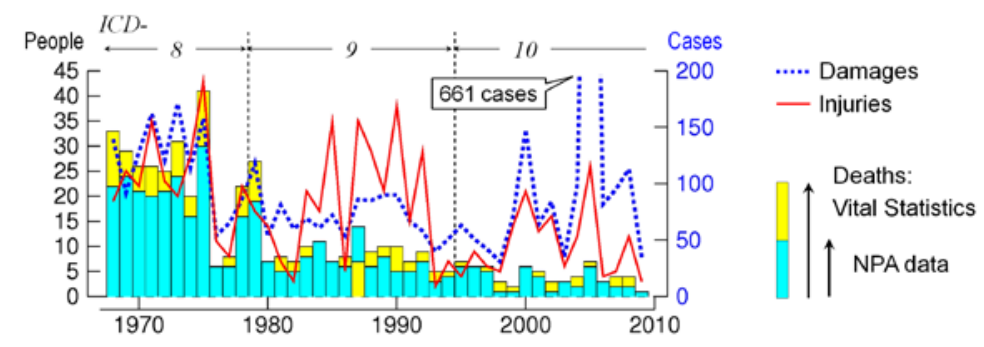

Fig.10 Annual lightning deaths, injuries, and damages based on the NPA data, shown in columns (left scale), red solid line (left scale), and blue dotted line (right scale), respectively. Deaths based on the Vital Statistics are also shown. The exceptional value (661 cases) of damages in 2005 is denoted by a callout.

In comparison, the decrease in lightning injuries in the NPA data is slower. The ratio of injuries to deaths in the last 10 years is about three times higher than that of the first 10 years. The decrease in damages is still weaker, with an indication of increase in the 2000s. However, the exceptionally large damage of 661 cases in 2005 is open to question. According to a report of National Association for Local Autonomy (2011), monetary damage by lightning in 2005 was no more than that of other years in the mid-2000s.

\section{RELATIONSHIP BETWEEN LIGHTNING MORTALITY AND METEOROLOGICAL PARAMETERS}

A series of correlation analyses was made for interannual variations in lightning mortality and meteorological parameters. In view of the rapid decreasing trend of mortality, correlation was not calculated for the whole period but for a moving window of fixed length, which was set to 15, 35, and 55 years. The missing values for 1944 to 1946 were simply ignored without changing the window size. Correlation was calculated after subtracting the linear trend of each quantity during the window period, in order to avoid the influence of long-term change. The reliability of the correlation coefficient was evaluated using the jackknife method (Appendix B). It is to be noted that a wider window size tends to result in higher statistical confidence for the same value of correlation coefficient.

Figure 11a shows the correlation coefficients for (1) lightning deaths and annual thunder days with a 15-year window, (2) lightning mortality rate and annual thunder days with a 15-year window, and (3) lightning deaths and annual thunder days with a 35-year window. The analysis period is from 1931 for the number of deaths, and from 1940 for the mortality rate. Each calculated value is assigned to the year at the center of the window (for example, the correlation for 1951 to 1965 is regarded as the value for 1958). Figure 11b shows the result of similar analyses based on warm-season thunder days instead. For both Fig. 11a and Fig. 11b, the results for the 15-year window indicate that lightning deaths have a positive correlation that is mostly above 0.5 until the 1960 s but decreases and loses significance after the middle of the 1970s as mortality decreases, although a significant correlation of about 0.6 is found for the last two periods (1999-2013 and 2000-2014). The results hardly change if mortality rate is used instead. For the 35-year window, significant correlation is obtained until the 1980s. Hereafter, the results based on warm-season thunder days are shown, with an understanding that similar results are obtained for annual thunder days. 


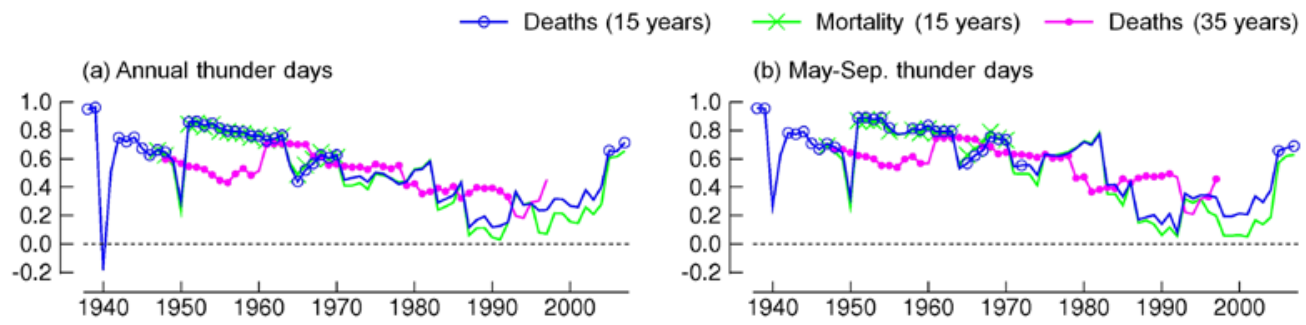

Fig.11 Correlation coefficients between lightning deaths and mortality, and (a) annual thunder days and (b) warm-season thunder days. Values significant at the $5 \%$ level are shown in circles and crosses.

Figure 12 shows the correlation calculated using the NPA data instead of the Vital Statistics. Results for damages are shown for two cases in which the extraordinary value of 2005 (661 cases) were included and discarded, respectively. For deaths, the result is almost the same as that obtained using the Vital Statistics (Fig. 11b), without significant correlation during the period covered by the NPA data. The correlation between injuries and thunder days is slightly higher than that for deaths, and is partially significant. For damages, a high correlation of about 0.8 is maintained until the end of the analysis period if the 2005 value is ignored (dotted line and crosses in light blue), although significant correlation is lost if the 2005 value is taken into calculation (dotted line in dark blue).

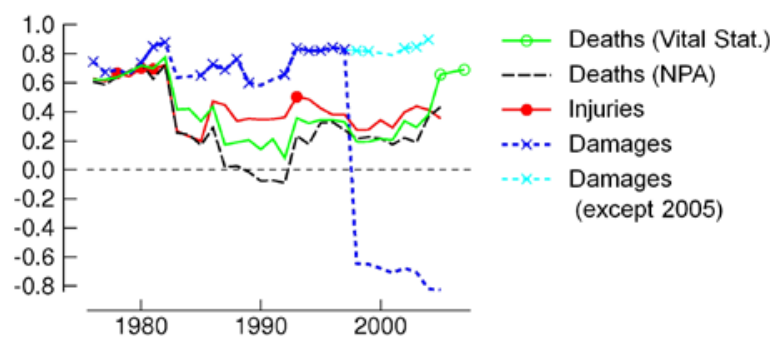

Fig.12 Correlation coefficients between lightning deaths, injuries, and damages from the NPA data and warm-season thunder days with a 15-year window. There is no significant value for deaths from the NPA data. For damages, results with and without the 2005 value are both shown in dark and light blue lines, respectively.

As another index of the relationship between lightning deaths and thunder days, the amplitude ratio of variations in the two quantities was defined by a regression

$$
\Sigma(\Delta y-a \Delta x)^{2} \rightarrow \min .,
$$

where $\Delta x$ and $\Delta y$ indicate the deviation of thunder days and lightning deaths from the linear trend of each quantity, summation is made over the window period, and $a$ is a regression coefficient corresponding to the amplitude ratio. Figure 13 shows the time series of $a$. The value of $a$ fluctuated at around 2 until the 1960s, namely for the period in which significant correlation exists. This fact means that lightning deaths vary by about $2 \%$ for a $1 \%$ variation in thunder days. The value of $a$ is also $2-3$ for injuries and damages using the NPA data (not shown). 


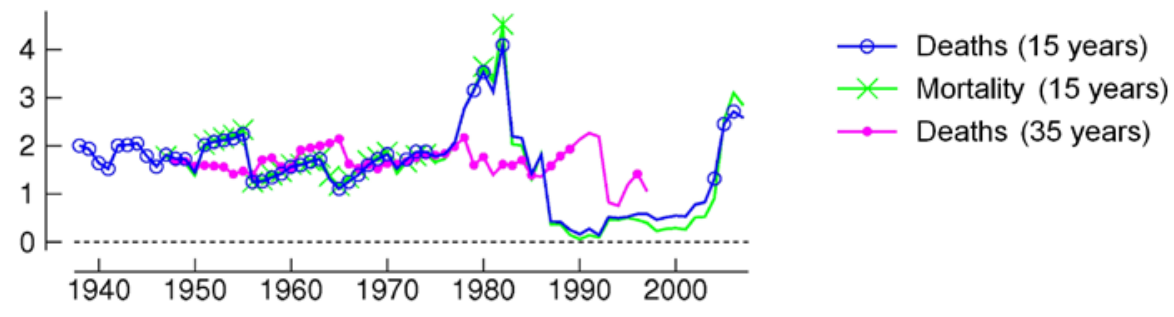

Fig.13 Same as Fig. 11b, but for proportional coefficients obtained from the regression of Eq. (1).

Figure 14 shows the correlation between lightning deaths and warm-season temperature, and precipitation amount. Until the 1980s, deaths and temperature have a positive correlation of 0.4-0.6, which is significant according to the 35-year window. In recent years, the correlation between deaths and temperature is insignificant, while lightning damages in the NPA data and temperature are positively correlated (if the 2005 value is ignored) with a correlation coefficient of about 0.4 , which is statistically significant if the 35-year window is used (not shown). The correlation between deaths and precipitation amount is negative and partially significant.

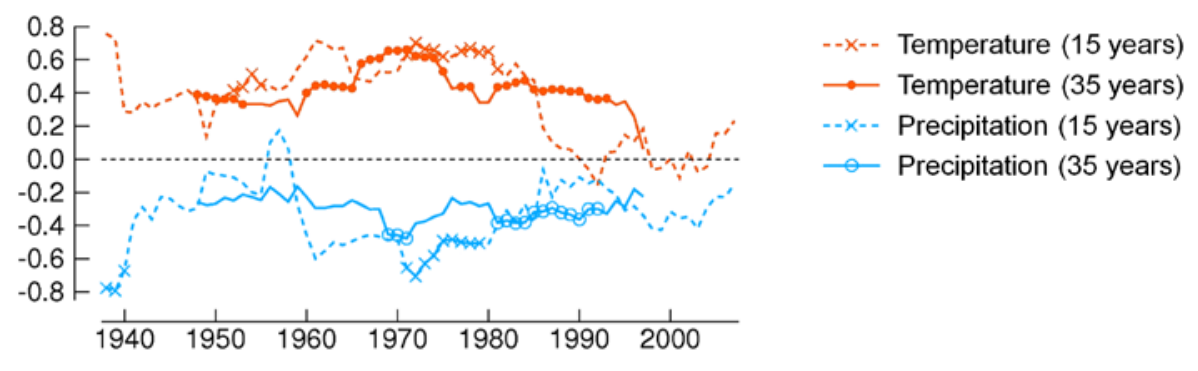

Fig.14 Correlation coefficients between lightning deaths, and warm-season temperature and precipitation amount.

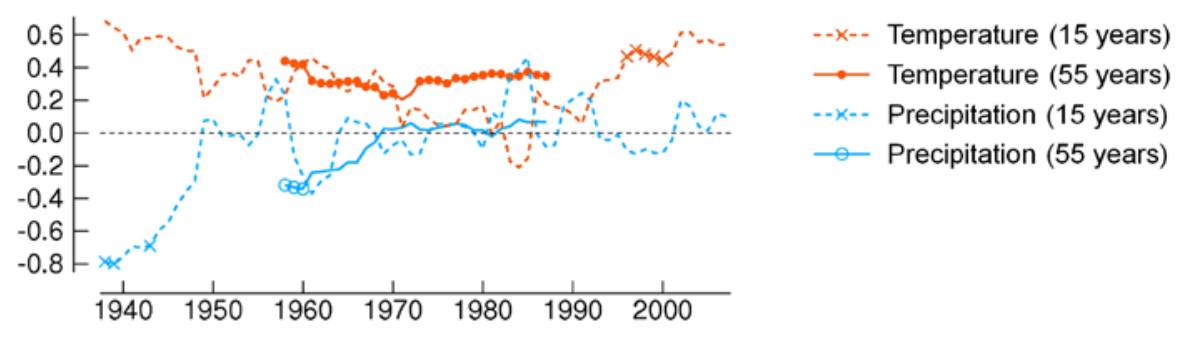

Fig.15 Correlation coefficients between warm-season thunder days, and temperature and precipitation amount. 


\section{F.FUJIBE}

As a supplement, a brief analysis was conducted for the relationship between thunder days and temperature, and precipitation amount. Figure 15 shows the correlation for the warm season. The correlation between thunder days and temperature is insignificant for the 15-year window, while it is significant with a value of about 0.3 for most of the analysis period if the 55-year window is used. The correlation between thunder days and precipitation amount is weak for most of the analysis period.

In view of the correlation among lightning deaths, thunder days, and temperature, a partial correlation analysis was attempted using the three quantities. The result changed little from that of the single correlation analysis, although statistical significance decreased. The partial correlation between deaths and thunder days is mostly insignificant for the 15-year window, but significant over most of the analysis period if the 35-year window is used. The situation was similar according to a partial correlation analysis for four quantities including precipitation amount.

Another supplementary analysis was made using thunder days at four stations in central Honshu (blue dotted line in Fig. 1b), where the mortality rate is highest in Fig. 8. The result was similar to that obtained using the 39 stations. The correlation between thunder days and mortality rate was statistically significant with a value of 0.6 or more for the period until the 1960s, but decreased afterwards.

\section{SUMMARY AND REMARKS}

(1) The long-term change in lightning mortality in Japan was described using the ICD-based Vital Statistics data for 1909 to 2014. The number of annual lightning deaths varied mostly between 20 and 60 people without a remarkable trend until World War II, while it exceeded a 100 in 1947 and 1948, and then decreased in nearly an exponential manner to less than 10 in recent decades. The rate of decrease in the mortality rate after 1947 is $7.0 \%$ /year, which corresponds to a decrease to $1 / 33$ in 50 years.

(2) The percentage of elderly people among lightning fatalities has increased after the mid-20th century. This increase is due to a slower decrease in mortality rate and a higher increase in the population of elderly people than those of young and middle-aged people.

(3) On the year-to-year variations, lightning deaths were positively correlated with thunder days until the 1960s, with a correlation coefficient of over 0.8 in some periods. After 1970, the correlation decreased and became insignificant as lightning deaths decreased. However, the number of lightning damages compiled by the National Police Agency (NPA) maintained a strong correlation ( $\sim 0.8)$ with thunder days until recent years, if the extraordinary value of 661 damages in 2005 is discarded from the analysis.

(4) Lightning deaths were positively correlated with temperature for most of the analysis period with a correlation coefficient of 0.4-0.6. This corresponds to a weak correlation ( $\sim 0.3)$ between thunder days and temperature. There was also a weak negative correlation between lightning deaths and precipitation amount for part of the analysis period.

The decreasing trend of lightning mortality has been reported for many other countries as well (Mackerras, 1991; Holle et al., 2005; Holle, 2008, 2010, 2016; Mills et al., 2008; Ashley and Gilson, 2009). For USA, the "best estimate" annual fatality by Ashley and Gilson (2009) shows a decrease to less than half during the period from 1959 to 2006. A similar change was reported by Mills et al. (2008) for Canada. Elsom (2015) showed a decrease in lightning deaths in UK to about $1 / 20$ of those in the mid-20th century. On a longer time scale, Holle et al. (2005) and Holle (2016) reported a decrease in lightning deaths in USA by an order of magnitude during the 20th century, and Elsom (2015) showed a decrease to about 1/100 in UK from the mid-19th century to the present. In comparison with these countries, the change in lightning mortality in Japan is characterized by a lack of remarkable change in the former half of the 20th century and a sudden increase just after World War II (1947 and 1948), followed by a decrease that was more rapid than that in USA and UK during the same period.

Elsom (2015) stated that "industrialised nations have experienced marked reductions in the annual number of lightning fatalities", but "changes in lightning fatality rates are much less in countries where people continue to engage in labour-intensive agriculture and fishing, live and work 
in ungrounded buildings”. Holle (2016) also described the difference in lightning mortality between developed and lesser-developed countries. The lifestyle of the Japanese people did not change significantly during the first half of the 20th century, especially in the countryside. The jump in lightning deaths just after World War II may be attributable to a temporary increase in agricultural workers in a situation where many people returned from outside the country due to the end of war, while agriculture was promoted in order to cope with a serious food shortage. It may also be related to poor housing after extensive war damage. In the latter half of the century, Japan underwent rapid industrialization that was accompanied by a drastic change in lifestyle including mechanization of agriculture. Figure 16 populations of Japan for 1920 to 2010 according to decadal data of the National Census. There was a gradual growth in total population with a nearly constant agricultural population until the middle of the 20th century, whereas the agricultural population began to decrease rapidly from 15\% of the total population in 1960 (13.7 million) to less than 2\% in 2010 (2.2 million). The change in lightning mortality appears to coincide with this change. It is also likely that development of weather forecast and communication devices, as well as disaster-resilient infrastructure, contributed to the reduction in lightning casualties.

The relative increase in elderly people in lightning deaths is another noticeable feature in our result. This may be partly related to the increase in the activity of elderly people. The percentage of $\geq 60$-year-old people among the agricultural population was $23 \%$ in 1960 , while it increased to $62 \%$ in 2010 according to the National Census. On the other hand, Holle et al. (2005) and Elsom (2015) discussed the shift in lightning casualties from agricultural workers to those in recreation activities. It is possible that a similar change has occurred in Japan. In this respect, the slower decrease in injuries and damages than deaths (Fig. 10) may reflect a change in the quality of lightning disaster, although it may be an apparent trend due to the increasing capture rate of minor incidents.

The high correlation between lightning mortality and thunder days in the mid-20th century (Fig. 11) was an unexpected result, because thunder days may be poorly representative of regional lightning activity as discussed in 2.2. The correlation decreased in the latter part of the analysis period, but this is likely to be due to the increase in statistical uncertainty as a result of decrease in mortality, since a high correlation has been maintained between lightning damages and thunder days. It will be interesting to use data from a lightning detection system in order to examine the relationship between lightning activity and damages in further detail.

The positive correlation between lightning deaths and temperature (Fig. 14) may reflect a tendency of higher convective activity in a warmer year, as a result of a greater amount of atmospheric moisture that is related to temperature through the Clausius-Clapeyron relationship (Fujibe, 2013, 2015). In addition, a warmer summer implies a greater number of sunny days, which is favorable for the outbreak of local thunderstorms. The latter explanation may also apply to the negative correlation between lightning deaths and precipitation amount, although the correlation is statistically significant for only a limited part of the analysis period.

\section{ACKNOWLEDGMENTS}

This study was supported by JSPS KAKENHI Grant Number 26220202.

APPENDIX A: Definition of Mortality Rate 
The mortality rate of five-year age category $k$ is defined by

$$
m_{k}=\frac{d_{k}}{p_{k}},
$$

where $m_{k}, d_{k}$, and $p_{k}$ are mortality rate, number of deaths, and population of the category, respectively.

For more than one age category, the unadjusted mortality rate is defined by

$$
M_{0}=\frac{\sum_{k} d_{k}}{\sum_{k} p_{k}},
$$

where summation is made over the categories considered. However, $M_{0}$ is unsuitable for time series analysis because it is affected by an uneven population change among ages. The adjusted mortality rate is defined by normalizing the population as

$$
M=\frac{\sum_{k} d_{k}\left(P_{k} / p_{k}\right)}{\sum_{k} P_{k}}=\frac{\sum_{k} m_{k} P_{k}}{\sum_{k} P_{k}},
$$

where $P_{k}$ is the population of category $k$ in the reference year, which has been set to 1985 in the formal statistics in Japan.

The present study is based on the adjusted mortality, which can be calculated for 1940 onward. For regional analysis (Fig. 8), however, the unadjusted mortality was used because data for prefectures were not categorized by age group.

\section{APPENDIX B: Jackknife Method}

The jackknife method consists of repeating the calculation of correlation by removing one of the years in the window period in turn, the result being a set of correlation coefficients $C^{\prime}[i](i=1, \ldots, N$; $N=$ window size), where $C^{\prime}[i]$ is the value obtained by removing the $i$ th year. Then, the unbiased estimate of $C^{\prime}$ and its variance, denoted by $\operatorname{Est}\left[C^{\prime}\right]$ and $\operatorname{Var}\left[C^{\prime}\right]$, respectively, are given by

$$
\begin{aligned}
& \operatorname{Est}\left[C^{\prime}\right]=N C^{\prime}[0]-(N-1) \mu, \\
& \operatorname{Var}\left[C^{\prime}\right]=(N-1) v,
\end{aligned}
$$

where $C^{\prime}[0]$ is the correlation obtained by using all the years in the window, and $\mu$ and $v$ are the mean and variance of $C^{\prime}[i]$ for $N$ trials (e.g., Efron and Tibshirani, 1993).

The difference between $C^{\prime}[0]$ and Est $\left[C^{\prime}\right]$ is usually less than 0.1 , but it can be larger for highly skewed data. The negative peaks at 1940 and 1950 in Fig. 11 are due to the outlying values in 1947 and 1948 , and are not found for $C^{\prime}[0]$. However, all of these values are statistically insignificant, so that the large

difference between $C^{\prime}[0]$ and Est $\left[C^{\prime}\right]$ does not matter in practice.

\section{REFERENCES}

Ashley, W. S. and C. W. Gilson, 2009. A reassessment of U.S. lightning mortality, Bull. Am. Meteorol. Soc. 90, pp.1501-1518.

Efron, B. and R. J. Tibshirani, 1993. An Introduction to the Bootstrap, Chapman \& Hall, p.436.

Elsom, D. M., 2015. Striking reduction in the annual number of lightning fatalities in the United Kingdom 
since the 1850s, Weather 70, pp.251-257.

Fujibe, F., 2013. Clausius-Clapeyron-like relationship in multidecadal changes of extreme short-term precipitation and temperature in Japan, Atmos. Sci. Lett. 14, pp.127-132.

Fujibe, F., 2015. Relationship between interannual variations of extreme hourly precipitation and air/seasurface temperature in Japan, SOLA 11, pp.5-9.

Hatakeyama, H., 1970. Kaminari no Kagaku [Science of thunder], Kawade Shobo Shinsha, p.259 (in Japanese).

Hayashi, S. and C. Marui, 2016. Frequency and seasonal variation of single lightning flash storm, "Ippatsurai”, in Japan, J. Atmos. Electr. 36, pp.13-22 (in Japanese with English abstract).

Holle, R. L., 2008. Annual rates of lightning fatalities by country, Preprint of the 20th International Lightning Detection Conference, April 21-23, 2008, Tucson, AZ, p.14.

Holle, R. L., 2010. Lightning fatalities in tropical and subtropical regions, Extended Abstract of the 29th Conference on Hurricanes and Tropical Meteorology, May 10-14, 2010, Tucson, AZ, 10.

Holle, R. L., 2016. A summary of recent national-scale lightning fatality studies, Weather Clim. Soc. 8, pp.35-42.

Holle, R., R. E. López, and B. C. Navarro, 2005. Deaths, injuries, and damages from lightning in the United States in the 1890s in comparison with the 1990s, J. Appl. Meteorol. p.44, 1563-1573.

Ishii, K., 2012. Statistical analysis of temporal and spatial distribution of cloud-to-ground lightning in Japan, Master's thesis, Univ. of Tsukuba, p.41 (in Japanese with English abstract).

Ishii, K., S. Hayashi, and F. Fujibe, 2014. Statistical analysis of temporal and spatial distributions of cloudto-ground lightning in Japan from 2002 to 2008, J. Atmos. Electr. 34, pp.79-86.

Japan Meteorological Agency, 1968. Raiu 10-Nenpo [Decadal thunder report], Japan Meteorological Agency, p.172 (in Japanese).

Japan Meteorological Agency, 2016. Guidelines for Meteorological Data Statistics, http://www.data.jma.go.jp/obd/stats/data/kaisetu/ (in Japanese).

Kitagawa, N., 1989. Long-term variations in thunder-day frequencies in Japan, J. Geophys. Res. 94, pp.13183-13189.

Kitagawa, N., 2001. Kumo to Raiun no Kagaku [Science of clouds and thunderclouds], Morikita Publishing Co., Ltd., p.144 (in Japanese).

Kobayashi, F., T. Shimura, and K. Masuda, 2007. Aircraft triggered lightning caused by winter thunderclouds in the Hokuriku coast, Japan - A case study of a lightning strike to aircraft below the cloud base -, SOLA 3, pp.109-112.

Mackerras, D., 1991. Occurrence of lightning death and injury, Andrews, C. J. et al., Lightning Injuries: Electrical, Medical, and Legal Aspects, CRC Press, pp.39-46.

Mills, B., D. Unrau, C. Parkinson, B. Jones, J. Yessis, K. Spring, and L. Pentelow, 2008. Assessment of lightning-related fatality and injury risk in Canada, Nat. Hazards 47, pp.157-183.

National Association for Local Autonomy, 2011. Recent Trend of Lightning Damages and Countermeasures, p.38, https://www.zzjk.jp/documents/lightning-strike.pdf (in Japanese).

Shindo, T., H. Motoyama, A. Sakai, N. Honma, J. Takami, M. Shimizu, K. Tamura, K. Shinjo, F. Ishikawa, Y. Ueno, M. Ikuta, and D. Takahashi, 2012. Lightning occurrence characteristics in Japan for 17 years: Observation results with lightning location systems of electric power utilities from 1992 to 2008, IEEJ Trans. Electr. Electron. Eng. 7, pp.251-257.

Taszarek, M., B. Czernecki, and A. Kozioł, 2015. A cloud-to-ground lightning climatology for Poland, Mon. Weather Rev. 143, pp.4285-4304.

Yoshida, H., 2002. Geographical distributions and long-term variations of thunder-day frequencies in Japan, Tenki 49, pp.279-285 (in Japanese). 